ORIGINAL ARTICLE

\title{
Increased osmolality of breast milk with therapeutic additives
}

\author{
L Srinivasan, R Bokiniec, C King, G Weaver, A D Edwards
}

Arch Dis Child Fetal Neonatal Ed 2004;89:F514-F517. doi: 10.1136/adc.2003.037192

See end of article for authors' affiliations

....................

Correspondence to: Professor Edwards, Department of Paediatrics, Imperial College London, Hammersmith Campus, Du Cane Road, London W12 ONN, UK; david.edwards@ic.ac.uk

Accepted 10 February 2004
Aim: To evaluate the changes in the osmolality of expressed breast milk (EBM) after the addition of seven additives and four proprietary fortifiers commonly used during neonatal intensive care.

Methods: The osmolality of $5 \mathrm{ml}$ EBM was measured with increasing doses of $6 \% \mathrm{NaCl}$, caffeine, sodium ironedetate, folic acid, and multivitamin drops. Sodium acid phosphate and chloral hydrate were added to $8 \mathrm{ml} \mathrm{EBM}$, and the fortifiers were added to standard volumes of EBM. Dose-effect curves were plotted, and the volume of milk that must be added to the above additives to maintain osmolality below $400 \mathrm{mOsm} / \mathrm{kg}$ was calculated.

Results: The osmolality of the pure additives ranged from 242 to $951 \mathrm{mOsm} / \mathrm{kg}$. There was a significant increase in the osmolality of EBM with increasing doses of all additives except caffeine. The osmolality of EBM with many additives in clinically used dosages potentially exceeded $400 \mathrm{mOsm} / \mathrm{kg}$. The greatest increase occurred with sodium ironedetate syrup, where the osmolality of EBM increased to $951.57(25.36) \mathrm{mOsm} / \mathrm{kg}$. Proprietary fortifiers increased the osmolality of EBM to a maximum of $395 \mathrm{mOsm} / \mathrm{kg}$.

Conclusion: Routine additives can significantly increase the osmolality of EBM to levels that exceed current guidelines for premature infant feeding. A simple guide for clinical use is presented, which indicates the amount of milk required as diluent if hyperosmolality is to be avoided.
B reast milk is the first choice for feeding preterm infants. The nutritional and immunological superiority of breast milk gives short term benefits ${ }^{12}$ and possible improved long term outcomes such as neurodevelopment ${ }^{3}$ and lower blood pressure. ${ }^{4}$ However, in neonatal practice, various additives are routinely combined with expressed breast milk (EBM) for therapeutic or nutritional benefit. These additives have the potential to increase the osmolality of EBM. The administration of hyperosmolar feeds is thought to be associated with necrotising enterocolitis. ${ }^{5-7}$ This concern led to recommendations that enteral feeds for neonates should not have osmolality above $400 \mathrm{mOsm} / \mathrm{kg}^{8}$ and so any intervention that increases the osmolality of EBM may be counterproductive.

White and Harkavy ${ }^{9}$ first recognised that the addition of medication to formula milk increased the osmolality by up to $300 \%$. Ernst et $a l^{10}$ measured the osmolality of both oral and intravenous preparations of 63 drugs and infant formulas. They confirmed that additions to formula milk significantly increased the osmolality of enteral feeds and showed that many of the drugs intended for oral administration induced increase in the osmolality of feeds that was 3 to 4 times higher than their corresponding intravenous preparations.

However, the available data do not give guidance on the osmolar effect of therapeutic and nutritional additions to EBM. The aim of this study was therefore to determine the effects of commonly used additives, drugs, and fortifiers, on the osmolality of EBM. We suggest a simple format that indicates the volume of milk needed as solvent to prevent the osmolality of EBM exceeding $400 \mathrm{mOsm} / \mathrm{kg}$ in clinically relevant doses of additives.

\section{METHODS}

This study was approved by The Hammersmith Hospital Trust research ethics committee. Seven samples of EBM, from seven different mothers, which were otherwise to be discarded were collected from Queen Charlottes and Chelsea Hospital Milk Bank, where they had been kept frozen at $-20^{\circ} \mathrm{C}$. The osmolality of each of these milk samples alone and with increasing doses of a series of additives were evaluated: $6 \% \mathrm{NaCl}$ (Sterile Fluids Unit (SFU), Edgware General Hospital, London, UK) containing $1 \mathrm{mmol}$ sodium in $1 \mathrm{ml}$; sodium acid phosphate (SFU, Edgware General Hospital) containing $0.9 \mathrm{mmol}$ phosphate and $1.5 \mathrm{mmol}$ sodium in $1 \mathrm{ml}$ solution; caffeine (SFU, Edgware General Hospital) containing $10 \mathrm{mg}$ in $1 \mathrm{ml}$; Dalavit (Eastern Pharmaceuticals, Coomb House, Isleworth, Middlesex, UK), a multivitamin preparation, $0.6 \mathrm{ml}$ containing vitamin $\mathrm{A}$ (palmitate 5000 units), vitamin B (thiamine hydrochloride $1 \mathrm{mg}$, sodium phosphate riboflavin BP $0.4 \mathrm{mg}$, pyridoxine hydrochloride BP $0.5 \mathrm{mg}$, nicotinamide B.P $5 \mathrm{mg}$ ), vitamin C (ascorbic acid BP $50 \mathrm{mg}$ ) and vitamin D (ergocalciferal BP 400 units); sodium ironedetate syrup (Link Pharmaceutical Ltd, Horsham, Sussex, UK), containing $5.5 \mathrm{mg}$ elemental iron in $1 \mathrm{ml}$, and folic acid syrup (Pharmacy Department, Hammersmith Hospitals NHS Trust) containing $2.5 \mathrm{mg}$ in $5 \mathrm{ml}$; chloral hydrate (Pharmacy Department, Hammersmith Hospitals NHS Trust) containing $200 \mathrm{mg}$ per $5 \mathrm{ml}$.

The osmolality of EBM containing appropriate doses of four proprietary human milk fortifiers was also measured: Nutriprem breast milk fortifier (one sachet in $50 \mathrm{ml}$ ); SMA breast milk fortifier (one sachet in $50 \mathrm{ml}$ ); Enfamil human milk fortifier (one sachet in $25 \mathrm{ml}$ ); Eoprotin (3 g in $100 \mathrm{ml}$ ).

Osmolality was determined from freezing point depression (Advanced TM microosmometer model 3300). The instrument was calibrated with aqueous $\mathrm{NaCl}$. When the osmolality exceeded $3000 \mathrm{mOsm} / \mathrm{kg}$, the substance was diluted 1:10 with distilled water. All measurements were performed in duplicate and averaged. If the difference was more than $2 \mathrm{mOsm} / \mathrm{kg}$, a third measurement was taken and the two closest readings were used.

All the additives were added to $5 \mathrm{ml}$ aliquots of EBM in increasing doses within the normal therapeutic range. The sodium acid phosphate solution was added to $8 \mathrm{ml}$ aliquots of EBM, and chloral hydrate was also added to $8 \mathrm{ml}$ EBM 

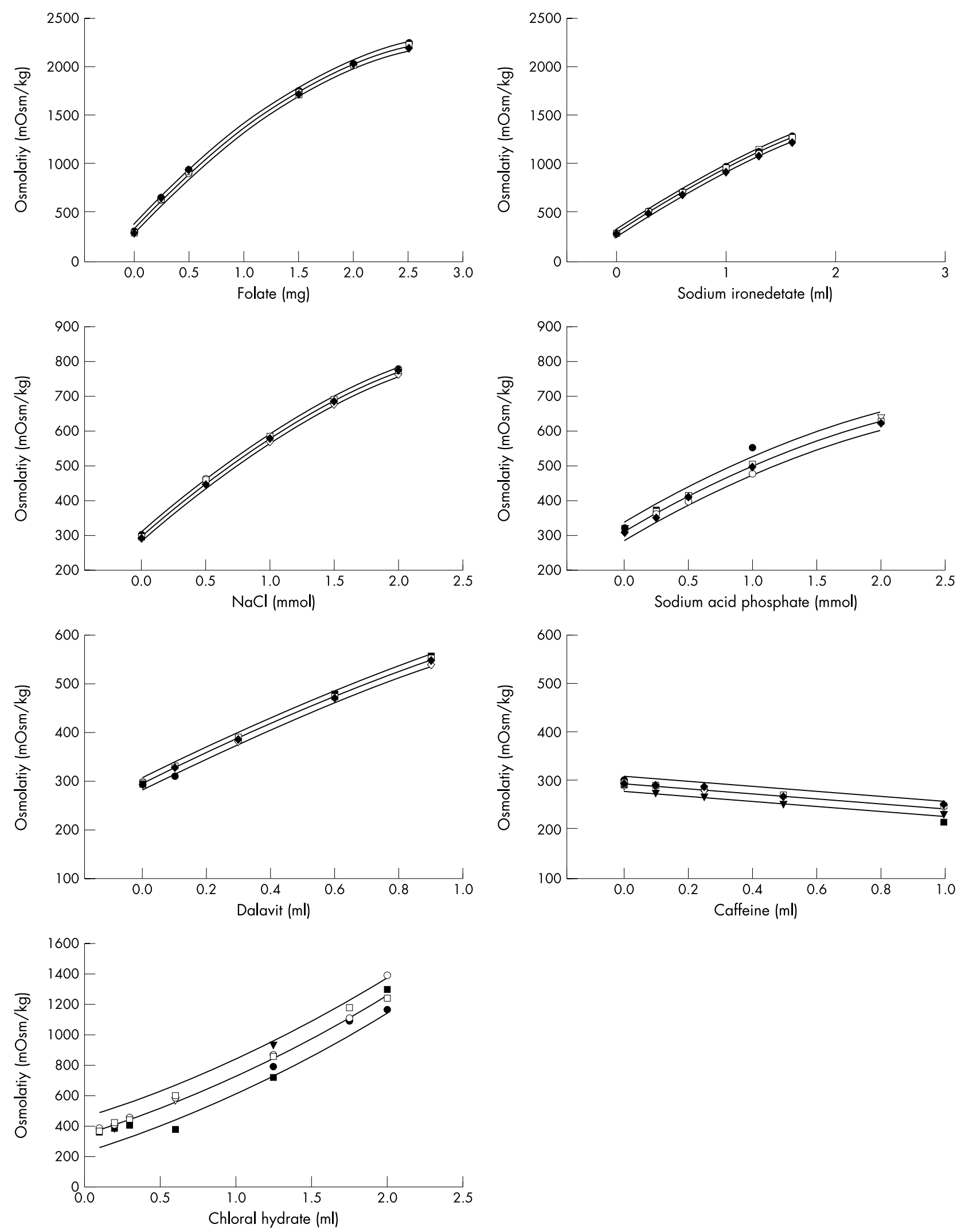

Figure 1 Osmolality of expressed breast milk with increasing doses of nutritional additives showing least squares linear regression and $95 \%$ confidence intervals.

because of its viscosity; the osmolalities were then extrapolated to $5 \mathrm{ml}$ EBM. Dose-effect curves with 95\% confidence interval were constructed by least squares linear regression analysis (Sigma Plot version 8.0: Jandel Scientific, San Rafael, California, USA). The volume of the EBM required to avoid an osmolality greater than $400 \mathrm{mOsm} / \mathrm{kg}$ when 
Table 1 Osmolality of each additive alone and in combination with a standardised volume $(5 \mathrm{ml})$ of expressed breast milk (EBM)

\begin{tabular}{|c|c|c|c|}
\hline Additive & $\begin{array}{l}\text { Osmolality of pure } \\
\text { additive (mOsm/kg) }\end{array}$ & Dose administered $(x)$ & $\begin{array}{l}\text { Measured osmolality of the mixture of } \\
\text { dose }(x)+5 \mathrm{ml} \mathrm{EBM}(\mathrm{mOsm} / \mathrm{kg})\end{array}$ \\
\hline $\mathrm{NaCl}$ & 1870 & $\begin{array}{l}1 \mathrm{mmol} \text { sodium } \\
2 \mathrm{mmol} \text { sodium }\end{array}$ & $\begin{array}{l}578.57(5.94) \\
763.42(5.53)\end{array}$ \\
\hline $\begin{array}{l}\text { Sodium } \\
\text { ironedetate }\end{array}$ & 3200 & $\begin{array}{l}1 \mathrm{ml} \text { iron, } 5.5 \mathrm{mg} \\
\text { elemental iron }\end{array}$ & $951.57(25.36)$ \\
\hline Dalavit & 2333 & $0.6 \mathrm{ml}$ & $472.71(4.91)$ \\
\hline Folic acid & 3410 & $500 \mu \mathrm{g}$ & $916.85(15.61)$ \\
\hline $\begin{array}{l}\text { Sodium acid } \\
\text { phosphate }\end{array}$ & 1541 & $0.5 \mathrm{mmol}$ phosphate & $654.40(6.53)$ \\
\hline Caffeine base & $\begin{array}{l}32.8 \\
16\end{array}$ & $\begin{array}{l}10 \mathrm{mg} / \mathrm{kg} \\
5 \mathrm{mg} / \mathrm{kg} \\
2.5 \mathrm{mg} / \mathrm{kg}\end{array}$ & $\begin{array}{l}242(13.55) \\
281.28(5.76) \\
266.71(5.9)\end{array}$ \\
\hline Chloral hydrate & 3780 & $\begin{array}{l}30 \mathrm{mg} / \mathrm{kg} \\
60 \mathrm{mg} / \mathrm{kg}\end{array}$ & $\begin{array}{l}691.25(29.57) \\
1382.50(23.75)\end{array}$ \\
\hline
\end{tabular}

typical clinical doses were added was calculated for each additive.

\section{RESULTS}

Table 1 gives the osmolality of the additives alone and in combination with a standardised volume of EBM $(5 \mathrm{ml})$. Figure 1 shows dose-effect curves for each additive on the osmolality of EBM $(8 \mathrm{ml}$ in the case of sodium acid phosphate and chloral hydrate and $5 \mathrm{ml}$ in the case of all other additives). Table 2 gives the osmolality of proprietary milk fortifiers added to standard volumes of EBM.

Osmolality increased with increasing doses of all additives except for caffeine, where the osmolality decreased with higher doses. The maximum increase in osmolality of EBM with the addition of a therapeutic dose occurred with chloral hydrate, where the osmolality increased to $1382.6 \mathrm{mOsm} / \mathrm{kg}$. The addition of proprietary fortifiers to EBM did not increase the osmolality above $400 \mathrm{mOsm} / \mathrm{kg}$.

Figure 2 gives a simple chart depicting the minimum amount of milk required for the dilution of commonly administered doses of additives if the osmolality is to remain below $400 \mathrm{mOsm} / \mathrm{kg}$.

\section{DISCUSSION}

This study shows that modification of EBM with therapeutic doses of commonly used additives can result in a significant increase in its osmolality. It is important to note that this study also suggests that the osmolality of EBM could be further worsened by the use of drugs and nutritional supplements in combination with fortified EBM.

White and Harkavy ${ }^{9}$ and Ernst et al ${ }^{10}$ noted high osmolality when certain drugs were added to formula feeds, largely due to the vehicle used in oral preparations, and previous studies have also evaluated the osmotic changes of breast milk with

Table 2 Osmolality of expressed breast milk (EBM) with addition of proprietary fortifiers

\begin{tabular}{ll}
\hline $\begin{array}{l}\text { Concentration of fortifiers } \\
\text { and volume of EBM }\end{array}$ & $\begin{array}{l}\text { Osmolality } \\
(\mathbf{m O s m} / \mathbf{k g})\end{array}$ \\
\hline $50 \mathrm{ml}$ EBM & 296.25 \\
$\begin{array}{l}\text { Nutriprem breast milk fortifier } \\
\text { (1 sachet in } 50 \mathrm{ml} \text { EBM) }\end{array}$ & 375.75 \\
SMA breast milk fortifier & 392.25 \\
$\begin{array}{l}\text { (1 sachet in } 50 \mathrm{ml} \text { EBM) } \\
\text { Enfamil human milk fortifier }\end{array}$ & 351.25 \\
(1 sachet in $25 \mathrm{ml}$ EBM) & 372.00 \\
Eoprotin supplement & \\
( $3 \mathrm{~g}$ in $100 \mathrm{ml}$ EBM) & \\
\hline
\end{tabular}

added fortifiers. ${ }^{11}{ }^{12}$ However, this study indicates that hyperosmolality can be avoided by the simple measure of dilution in sufficient volumes of EBM.

The osmolality of a solution can be described by the equation

$$
\mathrm{a}_{\mathrm{s}}=\mathrm{f}_{\mathrm{s}}\left(\mathrm{C}_{\mathrm{s}}\right)^{2}
$$

where $a_{s}$ is the effective concentration, $f_{s}$ is the activity coefficient, and $\mathrm{C}_{\mathrm{s}}$ is the analytical concentration. The effective concentration of the solute is due to the interactions of its molecules and ions with each other and water molecules, which in turn affects the colligative properties, such as freezing point depression. Hence ionic compounds such as $\mathrm{NaCl}$, which dissociates into two ions for each molecule, exert more osmotic pressure.

As expected, for most substances the osmolality rose with increasing concentration of the additive, but with caffeine the

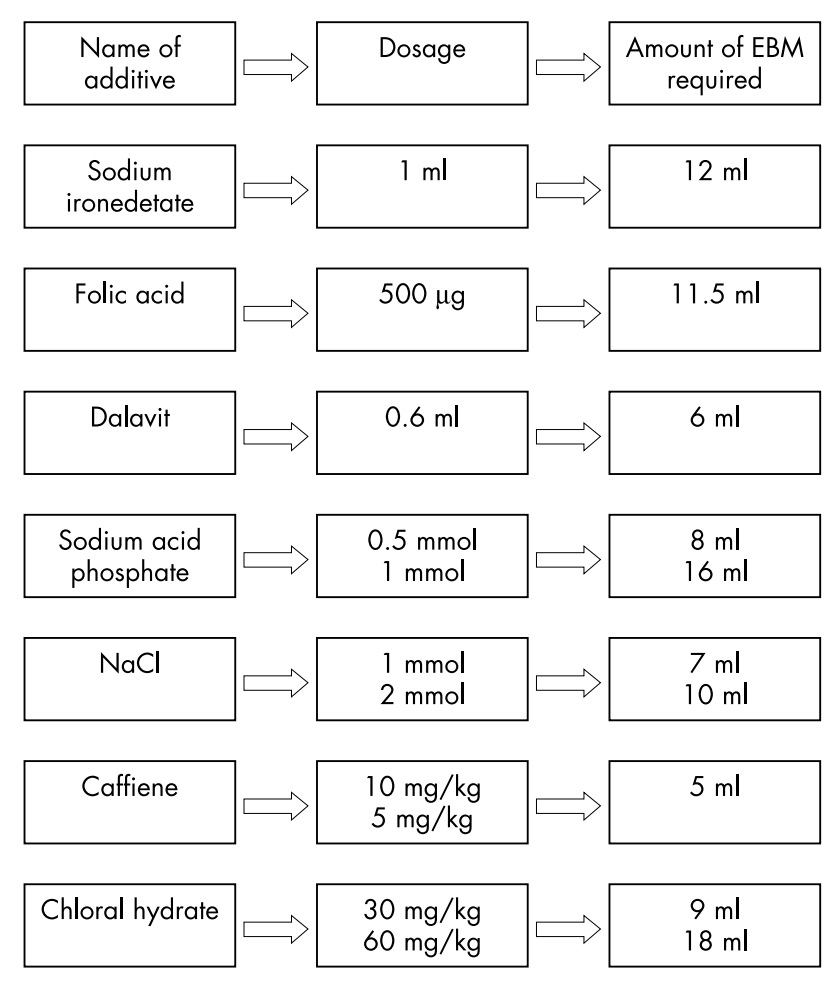

Figure 2 Amount of expressed breast milk required as solvent to maintain osmolality below $400 \mathrm{mOsm} / \mathrm{kg}$. 
opposite happened. This may be explained by certain physical properties of caffeine, such as increasing association equilibrium with increasing concentration and, being an organic compound, it does not dissociate into two or more ions. The decrease may also be related to the dilution effect.

Dose-response curves for different concentrations of fortifiers are not available in this study. The carbohydrate concentrations of fortifiers have recently been increased, leading to further concerns about the risk of necrotising enterocolitis. It is important to note that this study was performed with previously used fortifiers. There have also been concerns about the refrigeration of EBM with fortifiers and the resultant increase in osmolality. ${ }^{11}{ }^{12}$ In this study, the measurements were performed immediately after the addition of the fortifiers to EBM, as recommended.

The risks of hyperosmolar solutions to neonatal intestine have been documented in both animal and human studies..$^{57} 813$ As the fetal gut is exposed to the amniotic fluid which has an osmolality of about $275 \mathrm{mOsm} / \mathrm{kg}$ and the osmolality of human milk is similar, there is concern about the administration of enteral feeds with significantly higher osmolalities because of the risk of necrotising enterocolitis. In the light of these concerns, recommendations have been made that enteral feeds for neonates have osmolalities no greater than $400 \mathrm{mOsm} / \mathrm{kg}^{.}{ }^{8}$

The use of EBM lowers the incidence of necrotising enterocolitis, ${ }^{14}{ }^{15}$ and may improve neurodevelopment ${ }^{2}$ and lower blood pressure. ${ }^{3}$ It is postulated that the effects of the growth factors, trophic factors, and immunological factors of EBM on the intestine are responsible. It therefore seems appropriate to use breast milk, but maintain a low osmolality to avoid any risk of reducing these beneficial factors. Rational policies for the use of additives will allow this, and the chart provided in fig 2 suggests an approach that neonatal units could use to simplify safe additive administration.

\section{ACKNOWLEDGEMENTS}

Our thanks go to the nurses of the Neonatal Unit, Queen Charlottes and Chelsea Hospital for suggestions on the chart and to Dr M Ajayi-
Obe and Ms Oonagh Prendiville, Principle Biochemist BSc SRCS, for technical assistance.

\section{Authors' affiliations}

L Srinivasan, R Bokiniec, A D Edwards, Department of Paediatrics, Imperial College London, UK

C King, Department of Dietetics, Hammersmith Hospital, London, UK

G Weaver, Neonatal Intensive Care Unit Milk Bank, Queen Charlottes and Chelsea Hospital, Du Cane Road, London W12 ONN, UK

\section{REFERENCES}

1 Roberton NRC, 3rd ed. Textbook of neonatology. Edinburgh: Churchill Livingstone, 1999; 750.

2 Schanler RJ, Shulman RJ, Lau C. Feeding strategies for premature infants: beneficial outcomes of feeding fortified human milk versus preterm formula. Pediatrics 1999;103:1150-7.

3 Lucas A, Morley R, Cole TJ, et al. Breast milk and subsequent intelligence quotient in children born preterm. Lancet 1992;39:261-4.

4 Singhal A, Cole T, Lucas A. Early nutrition in preterm infants and later blood pressure: two cohorts after randomised trials. Lancet 2001;357:413-19.

5 Book LS, Herbst JJ, Atherton ST, et al. Necrotizing enterocolitis in low birth weight infants fed an elemental formula. J Pediatr 1975;87:602-5.

6 Willis DM, Chabot J, Radde IC, et al. Unsuspected hyperosmolality of oral solutions contributing to necrotizing enterocolitis in very low-birth-weight infants. Pediatrics 1977;60:535-8.

7 Le Guennec JC, Pare C, Billon B. Hyperosmolar formulas in necrotizing entercolitis. Am J Dis Child 1983;37:506.

8 Committee on Nutrition, American Academy Of Pediatrics. Commentary on breast feeding and infant formulas, including proposed standards for formulas. Pediatrics 1976;100:240-3.

9 White KC, Harkavy KL. Hypertonic formula resulting from added oral medications. Am J Dis Child 1982;136:931-3.

10 Ernst JA, Williams JM, Glick MR, et al. Osmolality of substance used in the intensive care nursery. Pediatrics 1983;72:347-52

11 Fenton TR, Belik J. Routine handling of milk fed to preterm infants can significantly increase osmolality. J Pediatr Gastroenterol Nutr 2002;35:298-321.

12 De Curtis M Candusso M, Pieltain C et al. Effect of fortification on the osmolality of human milk. Arch Dis Child 1999;81:F141-3.

13 Laker MF, Menzies IS. Increase in human intestinal permeability following ingestion of hypertonic solutions. J Physiol 1977;265:881-94.

14 Lucas A, Cole TJ. Breast milk and neonatal necrotising enterocolitis. Lancet 1990;336:1519-23.

15 McGuire W, Anthony MY. Donor human milk versus formula for preventing necrotising enterocolitis in preterm infants: a systematic review. Arch Dis Child Fetal Neonatal Ed 2003;88:F11-14. 